\title{
Evaluation of prescribing pattern of the private practitioners by the undergraduate medical students
}

\author{
Zaida Rahman', Rumana Nazneen' and Mahmuda Begum1 \\ ${ }^{1}$ Department of Pharmacology, Enam Medical College, Savar, Dhaka; ${ }^{2}$ Department of Obstetrics and Gynecology, \\ Holy Family Red Crescent Medical College, Dhaka, Bangladesh.
}

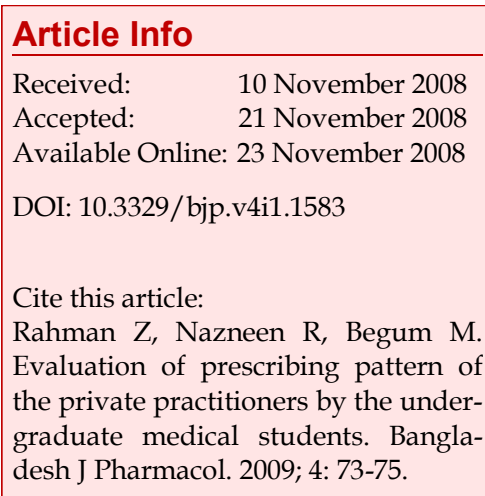

\section{Abstract}

To sensitize the fourth year undergraduate medical students about rational prescribing, 600 prescriptions of private practitioners were collected by them and analyzed using WHO/INRUD indicators. There were average 3.8 drugs per prescriptions. Drugs were prescribed in generic name only in 5 prescriptions. About $50 \%$ drugs were prescribed from the Essential Drug List; only $17.5 \%$ of prescriptions were complete in respect to patient medical information. Antibiotics were prescribed in $72.5 \%$ of the prescriptions; injections were prescribed in about $12.1 \%$ of the prescriptions. Although the exercise revealed few elementary aspects of the prescribing, the medical students participated in the exercise enthusiastically and perhaps understood the issues related to rational prescribing effectively.

\section{Introduction}

Medically inappropriate and economically inefficient use of medicines is observed throughout the world. These features are more marked in the developing countries like Bangladesh. Rational use of medicines is one essential element to be achieved to improve quality of health and medical care for the patients and the community (Ross-Degnan et al., 1992; Laing, 1990; Avorn et al., 1987).

Medical science in general and therapeutics in particular is developing very quickly and naturally undergoing fast transition. Therefore it has become imperative to train the physicians for self-directed learning (Joshi, 1996; Rahman and Rahman, 1993). Prescribing appropriate medicines for a disease condition and providing related information in a meaningful way to the patients should be regarded as the key 'transferable skills' to be achieved through Pharmacology courses (Rahman et al., 2000; Shankar et al., 2003). Generalized presence of irrationalities in prescribing indicates that traditional teaching in medical schools does not adequately prepare students for rational therapeutics. Most medical students do not have clear understanding on the skills required for prescribing a medicine for their patients or type of information they need to provide. This is usually because their pharmacology training has concentrated more on theory than on practical aspects of prescribing (de Vries et al., 1994). Prescribing behavior of the medical graduates depends upon how and what they have been taught and trained about drugs during their undergraduate course (Schwartz and Griffin, 1986). A survey had revealed that medical students felt the need for more teaching of therapeutics in the undergraduate medical curriculum (Ward and Miolszweski, 2002). Medical students should be helped to learn how to choose drugs appropriately for prescribing (Begum et al., 1999; de Vries, 1993; Rahman et al., 1998; Ramsay, 1993; WHO, 1993).

The current study was an attempt to teach the medical students the skills required to evaluate prescribing, whether appropriate or rational. To attain this skill, 'an exercise on prescription audit' was introduced as a teaching-learning strategy for the $4^{\text {th }}$ year M.B.B.S students of the Enam Medical College and Hospital where they collected, analyzed and audited prescriptions of the private practitioners on the basis of INRUD indicators (Anker et al., 1993). 
At the end of exercise the students should be able to analyze the prescribing pattern in order to assess the type and magnitude of irrational prescribing by the private practitioners of Dhaka city and to understand the principles of rational prescribing.

\section{Materials and Methods}

The $4^{\text {th }}$ year medical students of $\mathrm{EMCH}$ were divided into 6 groups, each group consisting of 7-8 students. Then each group was asked to collect 100 prescriptions of the registered physicians and specialists of different sectors at random within a period of one month. After a month, a total of 600 collected prescriptions of private practitioners were submitted. No attempt has been made to categorize the prescriptions according to patient's age, sex or disease profile. Afterwards, each group of students were given a period of 2 hours to analyze and audit the individual group results using the INRUD indicators. Then in the next practical class students compiled the individual group results into a combined one and audited the prescriptions using INRUD indicators.

\section{Results}

After compiling the results it was observed that there were average 3.8 drugs per prescriptions (Table I). Only in 5 prescriptions the drugs were prescribed in generic name; only $26.5 \%$ of prescriptions were complete in regard standard prescription format; only $50 \%$ drugs were prescribed from the essential drug list; only $17.5 \%$ of prescriptions were complete in respect to patient medical information. Antibiotics were prescribed in $72.5 \%$ of the prescriptions; injections were prescribed in about $12.1 \%$ of the prescriptions.

\section{Discussion}

The present study was a report of an exercise included in the practical portion of the pharmacology courses in the undergraduate medical curriculum 2005. The students of $4^{\text {th }}$ year MBBS class of Enam Medical College \& Hospital have collected, analyzed and audited 600 prescriptions of the private practitioners using INRUD indicators. Through the exercise the students revealed that most of the private prescribers did not follow the criteria of rational prescribing. On an average, 3.8 drugs were prescribed per prescription, which was 3.4 in a study conducted in 1996 (Baqui and Choudhury, 1996) and 3.3 in another study conducted in 1998 (Rahman et al., 1998). In a Nigerian study, the average number of drugs per case was 3.2 (Chukwuani et al., 2002).

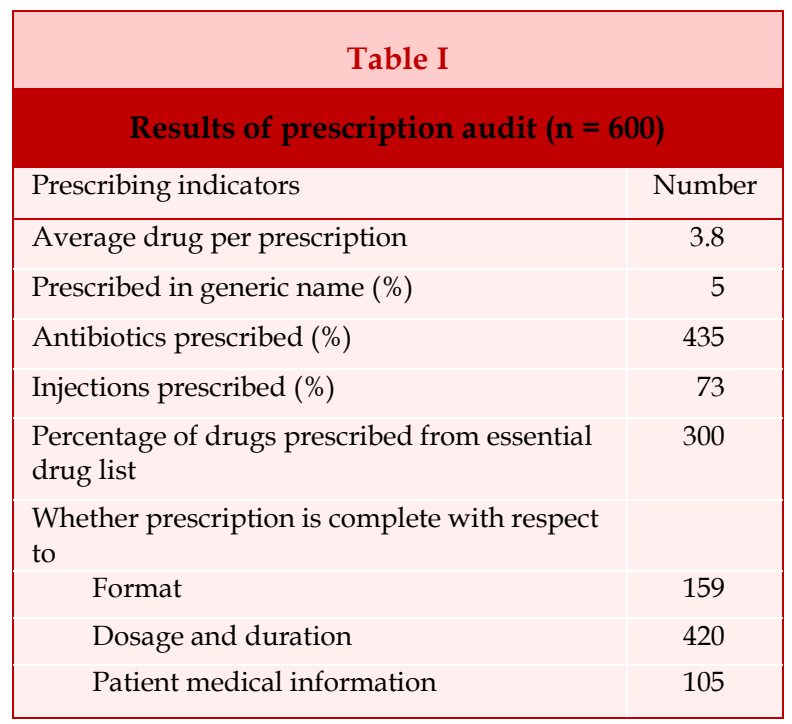

In the current study, the prescribers prescribed the drugs in generic name only in 5 prescriptions $(0.01 \%)$, which was much lower than $(4.1 \%)$ the finding of the previous study (Baqui and Choudhury, 1996). In the current study the students revealed that prescribers frequently prescribed antibiotics $(72.5 \%)$ in their prescriptions. This finding is in agreement with the study done by Baqui and Choudhury (1996) where the percentage of patients receiving antibiotics was $73.3 \%$. In an Iranian study (Ansari, 2001), percentage of patients receiving antibiotics was found high $(86.2 \%)$. However, all these findings do not correspond with the finding of a study conducted in 1998, which reported only $38.7 \%$ prescriptions contain antimicrobials (Rahman et al., 1998). In the present study, about 50\% of the drugs were prescribed from the Essential Drug List which was almost similar, i.e., $49 \%$ to the findings of Baqui and Choudhury (1996). About 12\% prescriptions contained an injection which were $9.7 \%$ (Baqui and Choudhury, 1996) and 8.2\% (Rahman et al., 1998). About $58 \%$ patients were provided with proper instructions regarding drug dosing and duration (Baqui and Choudhury, 1996), which has increased to $70 \%$. Nevertheless, only $17.5 \%$ prescriptions contained proper instructions about side effects of the prescribed drugs, other relevant advice and follow-up of the patients. These patient medical information parameters were never studied before in Bangladesh, therefore could not be compared.

From these observations it was evident that the prescribing pattern of the private practitioners is not improving regarding some particular parameters like generic prescribing, polypharmacy, use of antibiotics and provision of information. The reason of this irrational prescribing is perhaps due to the lack of knowledge of the private practitioners on 'how to prescribe a drug' and 'what information they should provide to their 
patients' (de Vries, 1994; Rahman et al., 1998). The present exercise was an attempt to educate the medical students about the methods and skills required to evaluate the prescribing pattern, which in turn is expected to improve the understanding and perception about rational prescribing among the future prescribers.

\section{References}

Anker M, Jokobowicz B, Fresle DA, Hozerzil HV. How to investigate drug use in health facilities; WHO/DAP/1993.

Ansari F. Use of systemic anti-infective agents in Iran during 1997-1998. Eur J Clin Pharmacol. 2001; 57: 547-51.

Avorn J, Harvey K, Soumerai SB, Herxheimer A, Plumridge R, Bardeley G. Information and education as determinants of antibiotic use: Report of Task Force 5. Rev Infect Dis. 1987; 9 (S3): S286-S96.

Baqui QBOF, Choudhury SAR. Prescribing pattern of graduate and non-graduate medical prescribers in rural Bangladesh. International Conferences on Improving Use of Medicines, 1996.

Begum M, Rahman MS, Islam AFM, Khan IA, Akter N. Eleven years of the undergraduate medical curriculum 1988: Review on the changes in pharmacology written questions. Bangladesh J Physiol Pharmacol. 1999; 15: 27-30.

Chukwuani CM, Onifade M, Sumonu K. Survey of drug use practices and antibiotic prescribing pattern at a general hospital in Nigeria. Pharm World Sci. 2002; 24: 188-195.

de Vries TPGM. Presenting clinical pharmacology and therapeutics: General introduction. Br J Clin Pharmacol. 1993; 35: 577-79.

de Vries TPGM, Henning RH, Hogerzeil HV, Fresle DA. Guide to good prescribing: A practical manual. WHO/DAP/ 94.11: 1994.

Joshi MP. Problem-orientated pharmacotherapy teaching. In: Essentials of medical education. Adhikari RK, Jayawickramarajah PT (eds). Kathmandu, Health Learning Materials Centre, 1996, pp 51-63.
Laing RO. Rational drug use: An unsolved problem. Trop Doctor 1990; 20: 101-03.

Rahman M, Rahman MS. Problem based learning: An overview. Bang Med J. 1993; 22: 12-15.

Rahman MS. Changes required in pharmacotherapy teaching to ensure rational use of drugs. Bang J Physiol Pharmacol. 1995; 11: 38-39.

Rahman MS, Begum M, Khan IA, Kamal ASMA, Choudhury S, Islam AMZ, Sultana R, Haque MZ, Akhter N. A baseline survey on use of drugs at private practitioner level in Bangladesh. Bangladesh J Physiol Pharmacol. 1998; 14: 4750 .

Rahman MS, Kamal ASMA, Choudhury S, Khan IA, Islam, AMZ, Sultana R, Begum M, Akhter N, Anwar AKMN. Exercise on selection of p-drug: Preliminary evaluation of a newer method of pharmacology teaching in Bangladesh. Bangladesh J Physiol Pharmacol. 2000; 16: 50-54.

Ramsay LE. Bridging the gap between clinical pharmacology and rational drug prescribing. Br J Clin Pharmacol. 1993; 35: 575-76.

Ross-Degnan D, Laing R, Quick J, Ali HM, Ofori-Adeji D, Salako L, Santosa B. A strategy for promoting improved pharmaceutical use: The international network for rational use of drugs. Soc Sci Med. 1992; 35: 1329-41.

Schwartz S, Griffin T. Medical thinking: The psychology of medical judgment and rational decision making. New York, Springer, 1986.

Shankar PR, Mishra P, Shenoy N, Partha P. Importance of transferable skills in pharmacology. Pharm Edu. 2003; 3: 97101.

Vance MA, Millington WR. Principles of irrational drug therapy. Int J Health Serv. 1986; 16: 355-61.

Ward F, Miolszweski K. Evaluation of the impact of pharmacist-led therapeutic tutorials on third-year medical students' knowledge and understanding of drugs used in clinical practice. Med Teach. 2002; 24: 628-33.

World Health Organization (WHO). Developing learning materials on rational use of drugs for medical and nursing schools: Report of an inter-country workshop. Geneva, World Health Organization, 1993. 